\title{
AQUELE QUE BUSCA A DEUS, O INCRÉDULO E O HONNÊTE-HOMME: NATUREZA E SOBRENATUREZA NESTES TRES TIPOS DE HOMEM ${ }^{1}$
}

\author{
Telma de Souza Birchal* \\ tbirchal@terra.com.br
}

\begin{abstract}
RESUMO $A$ intenção deste trabalho será de compreender a idéia de desnaturação, apresentada no fragmento La 427, no contexto da classificação pascaliana dos tipos de pessoa. A desnaturação é aí definida como uma perda do amor-próprio. Ora, se o amor-próprio, motor da busca da felicidade, define a natureza do homem decaído, fica o problema de compreender o paradoxal elogio ao amor-próprio levado a cabo por Pascal, neste fragmento, através da idéia de desnaturação.
\end{abstract}

Palavras-chave Pascal; Amor-Próprio; Natureza; Desnaturação; HonnêteHomme

RÉSUMÉ Ce travail examine l'idée de dénaturation, presentée dans le fragment La 427, à la lumière de la classification pascalienne des types de personne. La dénaturation y est définie comme une perte de l'amour-propre. Or, si l'amour-propre, moteur de la recherche du bonheur, définit la nature de l'homme déchu, il nous faut comprendre l'éloge paradoxal de l'amour-propre présent dans ce fragment, à travers l'idée de dénaturation.

Mots-clés Pascal, Amour-Propre; Nature; Denaturation; Honnête-Homme

* Professora do Departamento de Filosofia da UFMG. Artigo recebido entre $1^{\circ}$ e 30 de abril de 2006 e aprovado entre $1^{\circ}$ e 31 de maio de 2006.

1 O presente texto foi apresentado no "Coloque International Pyrrhonien, géométre, chrétien: Pascal, le scepticisme et l'honnêteté", realizado na Universidade de Caen, em fevereiro de 2004, com o apoio do Acordo CAPES-COFECUB entre os Departamentos de Filosofia da UFMG e da Universidade de Caen.

KRITERION, Belo Horizonte, nº 114, Dez/2006, p. 335-346. 


\section{Introdução}

Independentemente da discussão de fundo sobre o seu lugar no plano da Apologia pretendida por Pascal, os intérpretes associam o fragmento La 160 ao La 427 como desenvolvimentos distintos de um mesmo tema, qual seja, a “carta para levar a buscar Deus" (La 4). ${ }^{2}$ Daí sua importância para a discussão sobre o destinatário dos escritos de Pascal. ${ }^{3}$

O fragmento La 160 distingue “(...) três tipos de pessoas: umas que servem a Deus, tendo-o encontrado; outras que, não o tendo encontrado, se empenham em procurá-lo; outras que vivem sem procurá-lo nem tê-lo encontrado. Os primeiros são razoáveis e felizes, os últimos são loucos e infelizes. Os do meio são infelizes e razoáveis" (La 160).

O longo fragmento La 427, cuja análise faremos a partir de agora, atémse aos dois últimos tipos e dedica-se, em sua maior parte, à apresentação dos homens do terceiro tipo: aqueles que combatem a religião, que se recusam a buscar a Deus e que se instalam na indiferença, despreocupados com o destino de sua alma. Pascal deixa de lado aqui, portanto, aquele que, já tocado pela graça, encontra sua felicidade em Deus. Deixemos de lado também, por motivo de delimitação de nosso trabalho, o tema do cristão que vive neste mundo o horizonte da graça. ${ }^{4}$

$\mathrm{O}$ apologista abre o fragmento referindo-se a certos homens que fazem militância da incredulidade: "Que pelo menos procurem conhecer a religião que combatem, antes de combatê-la." Partindo do princípio natural, e aqui apenas implícito de que todos desejam a felicidade, nosso autor se espanta diante do fato de que eles não se interessem pelo destino eterno de sua alma:

A imortalidade da alma é uma coisa que nos importa tanto, que nos toca tão profundamente, que é preciso ter perdido todo o sentimento para ficar na indiferença de saber algo a respeito. (...)

2 Os intérpretes admitem que o fragmento La 427 seja um dos desenvolvimentos do bloco "Começo" e relaciona-se à carta citada em La 4 e 11. No entanto, divergem quanto ao lugar deste "Começo". Para Sellier, estes temas seriam tratados na abertura da Apologia. Para Antony Mac Kenna, o "Começo" e seus desenvolvimentos deveriam compor a introdução à Segunda Parte da Apologia. Ver SELLIER. L'ouverture de l'Apologie; e MACKENNA. Une question de cohérence: l'argument ad hominem dans les Pensées de Pascal, p. 25, nota 2. Os Pensamentos de Pascal são citados a partir da tradução de Mário Laranjeira (Editora Martins Fontes, 2001), com eventuais modificações.

3 Sobre o destinatário da Apologia, ver WETZEL. Pascal and desbelief: cathechesis and conversion in the Pensées. Especialmente sobre o fragmento 427, ver p. 275 et seq.

4 Uma contribuição importante para este problema encontra-se no artigo de MACKENNA. Une question de cohérence: l'argument ad hominem dans les Pensées de Pascal, p.35-37, onde a fé se define pelo costume. 
E eis porque, entre aqueles que não estão persuadidos disso, faço uma extrema diferença entre os que trabalham com todas as forças para instruir-se e os que vivem sem se dar a este trabalho e sem pensar nisso. (grifo nosso)

Definem-se, portanto, dois tipos de homem. Do que se segue no texto, fica claro que aqueles que "gemem sinceramente nessa dúvida" agem de acordo com a natureza humana, pois "(...) se deve ter esse sentimento" - a palavra reaparece aqui - "por um princípio de interesse humano e por um interesse de amor-próprio". A preocupação com o destino da alma não é, explica Pascal, uma questão de "zelo piedoso" ou de "devoção espiritual", mas sim a tradução mais razoável do princípio que define a condição humana decaída: a busca da felicidade movida pelo amor-próprio.

De forma que o primeiro tipo, o que busca ou procura, representa a condição humana, a natureza decaída, cercada de dúvidas e condenada à busca, em relação a qual a segunda figura, a do indiferente e incrédulo, parece a Pascal tão absurda que ele tem dificuldade em defini-la: "Essa negligência num assunto em que se trata deles mesmos, de sua eternidade, de seu todo, me irrita mais do que me comove; causa-me admiração e espanto; é para mim um monstro. (...) não tenho termos para qualificar uma tão extravagante criatura."

A figura do segundo tipo de homem vai ganhando cores mais fortes no discurso que Pascal lhe atribui posteriormente, cujas marcas são a ignorância quanto à sua condição e seu destino e a satisfação nessa ignorância. Pode-se afirmar que o tipo aí retratado seja representativo de uma atitude compartilhada pelos libertinos, céticos e deístas do século XVII: a despreocupação com o destino eterno da alma. ${ }^{5}$ Com essa descrição, Pascal quer mostrar ao seu interlocutor que tal atitude é incompreensível e irracional e, assim, levá-lo à procurar Deus.

O que nos interessa, porém, é a definição que o autor de os Pensamentos nos apresenta deste estado, como constituindo uma corrupção da natureza: "Ora, sustento que (...) eles servem pelo menos admiravelmente para mostrar a corrupção da natureza, por sentimentos tão desnaturados. (...) que haja homens indiferentes à perda de seu ser e ao perigo de uma eternidade de misérias, isso não é natural." Pascal fala ainda de uma "estranha reviravolta da natureza do homem", e conclui que a causa desse comportamento é sobrenatural: "É um encantamento incompreensível e um entorpecimento sobrenatural que marca uma força onipotente que o causa." ${ }^{\prime \prime}$ (grifo nosso) 
Depois disso, Pascal estabelece uma diferença, no interior da categoria daqueles que não buscam, entre os realmente desnaturados e aqueles que a eles "se misturam, mas não são realmente assim. Esses últimos apenas fingem ter esses sentimentos em busca da estima dos outros - já que há uma valorização, no contexto intelectual de Pascal, da atitude de "sacudir o jugo" da religião - e são levados a "contrariar a sua natureza". Segundo muitos intérpretes, Pascal estaria aqui retratando o honnête-homme, ${ }^{7}$ que seria o real destinatário da Apologia. Vemos surgir no final do fragmento La 427 um tipo de pessoa diferente, tanto daquele que busca a Deus quanto do incrédulo ou libertino, e que também não se encaixa bem nas três categorias definidas em La 160. Esse tipo - supostamente o honnête-homme - compreende aqueles que podem ser levados a buscar, pois não estão totalmente corrompidos.

Feita esta breve retomada dos pontos que nos interessam do fragmento La 427, trata-se de compreender agora a idéia de desnaturação aí presente, pois ela leva Pascal a fazer uma espécie de elogio bastante problemático ao amor-próprio, considerado o contexto agostiniano no qual se situam os Pensamentos. Sabe-se bem que, para Agostinho e para Pascal, o amorpróprio, uma das formas da concupiscência, se opõe ao amor de Deus, ou à caridade. ${ }^{8} \mathrm{O}$ amor-próprio é, em geral, objeto de críticas severas de Pascal. Basta-nos lembrar, por exemplo, o extenso fragmento La 978, o qual, segundo Jean Mesnard, "conduz a ver no amor de si, através do jogo da bajulação de si mesmo e dos outros, ao qual o amor de si recorre constantemente, o contrário do amor à verdade, o princípio de uma mentira universal corruptora das relações humanas". ${ }^{9}$ Quanto ao "eu", definido pelo amor-próprio, Pascal exigirá, em outro lugar, que Mitton, um honnête-homme, o extirpe, e não somente o esconda (La 597). Como compreender então, no fragmento La 427, o elogio, embora indireto, ao "interesse de amor-próprio" que se faz mediante a acusação da desnaturação daqueles que não o possuem?

Podemos levantar duas hipóteses: Na primeira, a desnaturação representaria uma negação do amor-próprio, no caso, seu aniquilamento; nesse caso, porém, ela estaria mais próxima da santidade que da corrupção descrita

7 Os termos honnête-homme e honnêteté, correntes no século XVII, são de difícil tradução. Mário Laranjeira propõe que se traduza honnêteté por fidalguia. O termo sugere a idéia de civilidade, mas também de integridade. No honnête-homme, a educação vai além das fórmulas de polidez, manifestando uma verdadeira formação do caráter; o cultivo das ciências e das letras não se traduz em ostentação erudita, mas num saber universal e pertinente. Optamos, aqui, por manter termo em francês. Nos Pensamentos, ver os fragmentos La 611, La 647 e La 778.

8 SELLIER. Pascal et Saint-Augustin, p.140-146. Ver artigo de Jean-Robert Armogathe nesse volume. Sobre o amor-próprio, ver fragmentos La 597, La 373, La 220, La 372, La 380, La 381 e La 564.

9 MESNARD. Les origines grecques de la notion d'amour-propre, p. 43. 
por Pascal. Na segunda, ela seria uma desnaturação no interior mesmo da experiência do amor-próprio, o que nos parece mais verossímil. Para investigálas, comecemos por perguntar o que define, em Pascal, a esfera da natureza.

\section{Aquele que busca e a natureza decaída}

Pascal, com a tradição, entende que a busca da felicidade define a natureza humana:

Todos os homens procuram ser felizes. (...) É o motivo de todas as ações de todos os homens, até daqueles que vão se enforcar (La 148).

Ora, a busca da felicidade é motivada pelo amor-próprio, é o lugar por excelência da manifestação daquele. Por sua vez, o amor-próprio caracterizase por sua infinitude, o que mostra a injustiça do "eu" que "se faz centro de tudo" (La 597). Seguindo essa linha de pensamento de Pascal, podemos afirmar que a aspiração à felicidade, justamente naquilo que ela tem de infinito e de insaciável, é antes sinal da miséria que da grandeza do homem; é antes signo da condição decaída e só num segundo momento, e por derivação, signo de sua origem divina.

Para fundamentar essa afirmação, retomemos o importante texto sobre o amor-próprio na Carta sobre a morte do pai: "Deus criou o homem com dois amores, um por Deus e outro por si mesmo; mas com esta lei, que o amor por Deus seja infinito, quer dizer sem nenhum fim senão o próprio Deus, e que o amor por si mesmo seja finito e se reportando a Deus." ${ }^{10} \mathrm{O}$ amor-próprio, no estado de criação, é limitado pelo amor a um outro, Deus. Com a queda, o amor-próprio se estende sobre o vazio deixado pelo amor de Deus e se torna infinito, ou seja, tem a si mesmo como fim. Ora, uma das características desse infinito, no estado decaído, é a inconstância, o sentimento do vazio, a insatisfação, pois "esse abismo infinito não pode ser preenchido senão por um objeto infinito e imutável, quer dizer, pelo próprio Deus" (La 148). O infinito do desejo só encontra seu limite diante de seu verdadeiro objeto. ${ }^{11}$

Neste ponto coloco em questão a interpretação do tema do infinito da vontade apresentada por MacKenna, num texto por outras razões notável e

10 PASCAL. Lettre écrite à l'occasion de la mort de M. Pascal le Pére, p.277. Sobre este ponto, nos restringimos a lembrar as belas páginas de Philippe Sellier sobre o tema dos dois amores. SELLIER. Pascal et Saint Augustin, p.140-146.

11 Ver, a esse respeito, artigo de minha autoria: "A marca do vazio: reflexões sobre a subjetividade em Blaise Pascal". 
já aqui referido. ${ }^{12} \mathrm{O}$ intérprete percebe na dualidade pascaliana da grandeza e da miséria uma tradução da problemática cartesiana do infinito e do finito: "Como o sujeito cartesiano, o homem pascaliano 'sente' em si um princípio de excelência que é a infinitude de sua vontade, uma aspiração à felicidade, e observa sua própria incapacidade de satisfazer a essa aspiração." ${ }^{13}$

No entanto, acreditamos que a questão do desejo não encontra em Pascal uma formulação tão inequívoca, de forma que se possa identificar nele um elogio ao infinito do desejo ou da vontade - deixando de lado, para os fins que pretendemos aqui, a necessidade de distinguir entre os dois termos. Se há, sem dúvida, uma dualidade no significado do desejo, se ele é sinal da falta, mas também marca de "que houve outrora no homem uma felicidade verdadeira" (La 148), a dualidade pascaliana é bem diferente da dualidade cartesiana. Vejamos.

Em Pascal, não apenas a incapacidade de preencher a aspiração à felicidade é uma marca da miséria, mas a aspiração, ela mesma, também o é. Toda aspiração é imediatamente uma falta; a felicidade está no repouso, e não na busca, como mostram os fragmentos sobre o divertimento. A primeira natureza se define pela felicidade, a segunda pela busca, e toda busca se faz necessariamente no horizonte da falta; daí que, neste caso, Pascal é mais platônico que cartesiano. O desejo é a experiência da falta, a natureza é desejo, e o desejo se traduz como amor-próprio. Daí que o exercício do desejo não pode ser, ou não pode ser exclusivamente, uma marca da primeira natureza ou da grandeza do homem. Daí que o "eu" do amor-próprio, que nos leva à busca da felicidade, seja odiável. O ideal de Pascal não é regular o "eu”, mas extirpá-lo.

É preciso, porém, ao modo de Pascal, lembrar-se da verdade contrária: o desejo é marca do rei destronado, ele aponta para a primeira natureza que, no entanto, é grande não em si mesma, mas em outro. ${ }^{14}$ A grandeza do homem não está propriamente em seu desejo infinito, mas no objeto deste desejo.

Com essa exposição queremos fundamentar a idéia de que o desejo e a busca da felicidade se inscrevem na esfera da natureza decaída, da qual a

12 Comentando os blocos "Miséria", "Grandeza" e "Contrariedades", o intérprete afirma que Pascal traduz Descartes: "A idéia de infinito deixa, segundo Descartes uma marca concreta na natureza humana: é uma 'aspiração a algo de melhor e de maior do que o que sou', aspiração que caracteriza sua vontade infinita. Descartes então descobre, no cogito, um ideal de perfeição absoluta (o Ser infinito e necessário) e a consciência de sua própria imperfeição. Esta dupla descoberta é traduzida por Pascal em termos de instintos contrários (instinto ao repouso e ao tumulto - T. B.)", p. 33. Ver La 136.

13 MACKENNA. Une question de cohérence: l'argument ad hominem dans les Pensées de Pascal, p.33.

14 "Somos incapazes de não desejar a verdade e a felicidade e somos incapazes de certeza e de felicidade. Esse desejo nos é deixado tanto para nos punir quanto para fazer-nos sentir de onde caímos." (La 401) 
figura paradigmática é o homem que busca. Na prática, o exercício do desejo não revela nenhuma grandeza no sentido positivo: todo exercício de busca da verdade está cercado pelas potências do engano, e é por isto que o que se busca merece, da parte de Pascal, apenas compaixão.

Logo, é menos na esfera de uma sobrenatureza apenas sinalizada e mais na esfera da natureza que se deve procurar o elemento que permite o elogio do amor-próprio na figura da pessoa que busca. Ela encarna o "senso comum" e os "sentimentos da natureza" (La 428), imagem da razoabilidade que serve para tornar mais evidente a loucura de incrédulo. O importante a se observar, neste ponto, é que a razoabilidade que Pascal atribui à figura do homem que busca se ancora num sentimento de infelicidade. Por causa desse sentimento, esta figura torna-se compreensível e escapa da categoria do monstruoso, na qual se inscreve o desnaturado. O primeiro tipo de pessoa é aquele que compreendeu que "não há aqui satisfação verdadeira e sólida, que todos os nossos prazeres não passam de vaidade (...)" e que "não existe bem nesta vida a não ser na esperança de outra vida" (La 427), que sofre e que se inquieta com isso e parte em busca de uma solução. A infelicidade é uma decorrência natural da experiência do fracasso e causa da busca de Deus.

Logo, o amor-próprio daquele que busca tem duas dimensões: por um lado, ele é desejo, movimento ilimitado; por outro, ele é experiência da infelicidade, que se realiza como capacidade de refletir sobre si mesmo, de se conhecer e de conhecer seu fracasso e, portanto, de transformar a busca infinita de objetos finitos em busca de Deus. A contrariedade, marca da natureza, caracteriza também o amor-próprio natural. ${ }^{15}$

\section{O incrédulo e a desnaturação do amor-próprio}

O contrário ocorre na figura do homem desnaturado. Voltando ao fragmento La 427, lemos que ele conhece sua condição e a realidade da morte; no entanto, não tem a mínima preocupação com o único assunto que deveria lhe interessar: o destino de sua alma. E o faz de forma explícita e consciente: "Pois se ele estiver com isso muito tranqüilo e satisfeito, se fizer disso profissão, e afinal se fizer disso o motivo de sua alegria e vaidade, não tenho termos para

15 Lembremos, com Hélène Michon, que a contrariedade, a diversidade, a não coincidência consigo definem a essência mesma da natureza humana decaída: "O homem se vê, assim, infinitamente distante de si mesmo. Longe de fazer explodir (éclater) a noção de natureza humana, Pascal a faz consistir na própria explosão, nessa distorção que todo homem descobre em si mesmo. O próprio da natureza humana será assim essa distância de si a si." MICHON. L'ordre du cœur: philosophie, théologie et mystique dans les Pensées de Pascal, p. 44. 
qualificar tão extravagante criatura." O incrédulo só tem uma dimensão do amor-próprio, o desejo: ele passa de uma preocupação à outra, de um objeto a outro e se contenta com tal situação, com o próprio movimento. $\mathrm{O}$ homem desnaturado é aquele que perdeu a capacidade de ser infeliz ou de sentir a infelicidade de sua condição, ou seja, cujo amor-próprio é incapaz de fazer o retorno sobre si, de refletir e sofrer com o seu vazio. Ele tem "ao mesmo tempo essa sensibilidade pelas menores coisas e essa estranha insensibilidade pelas maiores". De forma que o fragmento em análise apresenta-nos a figura de um homem sem Deus que, se não é feliz, é, pelo menos, "tranqüilo e satisfeito", não previsto no fragmento La 160 .

O ímpio não será tocado pelo discurso dramático da desproporção do homem, porque se contenta com o finito. Ele é "irracional" porque "insensível", ou seja, é a corrupção do sentimento que o torna irracional, o que mostra ainda aqui a centralidade do tema do sentimento em Pascal. Ora, a origem de tal fenômeno só pode ser sobrenatural porque, pela simples natureza, o fracasso em nossa busca da felicidade deve levar-nos à infelicidade. Ou, nas palavras de Thirouin: "É para o homem marca de sua grandeza jamais estar suficientemente privado da verdade que não possa sentir dolorosamente o estar dela privado." ${ }^{16}$ Essa dor o incrédulo perdeu, de forma sobrenatural.

A corrupção da corrupção - ou a corrupção do amor-próprio - instaura então, em primeiro lugar, uma espécie de unidimensionalidade, oposta à contradição que define a natureza humana. Incapaz de sofrer seu vazio, o amor-próprio corrompido não vê sua outra verdade, ou seja, sua insuficiência, em todo seu significado: e continua na busca das coisas finitas.

Em segundo lugar, digamos que a corrupção do amor-próprio significa a perda do caráter infinito, da insaciabilidade que marca o amor-próprio natural, conforme visto anteriormente, a partir da Carta sobre a morte do pai. $\mathrm{O}$ amor-próprio corrompido é finito, não no sentido original de limitado por outro amor, mas no sentido de completo em si mesmo e, portanto, capaz de proporcionar ao descrente um contentamento com o temporal. Assim, o que o descrente não experimenta é a própria infinitude, traço vazio da grandeza do homem e abertura para a alteridade. 


\section{L'honnête-homme}

Já nos referimos ao outro tipo de pessoa, delineado ao final do fragmento La 427: aquele que imita as maneiras dos descrentes, em busca da estima e da admiração dos outros homens. Eles querem ser reconhecidos por "ter sacudido o jugo" da religião. O tema da busca da estima é introduzido pela primeira vez neste texto. Ora, agradar e se fazer amar é o objetivo maior dos assim chamados honnêtes-hommes, pois reconhecem a necessidade natural que todo ser humano tem da estima do outro, como demanda de seu amorpróprio. Nas palavras do Chevalier de Méré, um dos honnêtes-hommes do círculo de Pascal: "Para eles, é suficiente como objetivo levar a alegria a todo lugar, e seu maior cuidado é dedicado a merecer a estima e a se fazer amar." 17 No entanto, eles sabem bem que só se alcança a estima dos outros se o amorpróprio é regrado, se ao amor-próprio dos outros é concedido o seu lugar. ${ }^{18}$

Sabemos que, em outras passagens, Pascal ataca a idéia de amor-próprio em seu cerne, mostrando: 1- a vaidade e a falta de fundamento presentes na atitude de "estimar mais a estima dos homens que a busca da verdade" (La 151); 2- a impossibilidade de conquistar esta estima (La 805); e 3- a injustiça do amor-próprio presente no ideal de l'honnêteté (La 597, La 617). ${ }^{19}$ No fragmento em questão, no entanto, o autor aceita, pelo menos provisoriamente, a finalidade que o honnête-homme coloca para si e apenas questiona seus meios: Pascal tenta convencê-lo de que, para alcançar a estima dos homens, o caminho da fé é melhor que o da descrença. Assim, ele apela ao amor-próprio para chamar o seu interlocutor à razão e levá-lo a buscar.

Qual é, então, o lugar do honnête-homme neste fragmento, já que este se distingue tanto do que busca, pois efetivamente não está à procura de Deus, quanto dos libertinos, pois esconde que sofre com a dúvida a respeito do destino da sua alma?

A julgarmos pelos retratos dos honnêtes-hommes traçados pelos pesquisadores contemporâneos, poderíamos pensar que aqueles se aproximam dos incrédulos e libertinos. Como nos lembra Pintard, o honnête-homme se define por buscar a felicidade e por uma "indiferença tranqüila aos fins últimos

17 MÉRÉ. De la vraie honnêteté, p,70.

18 "O 'honnête-homme' percebe com lucidez seus próprios desejos e sabe que eles engendram necessariamente tensões na sociedade. Ele se conhece a si mesmo. Ele não quer no entanto colocar em causa seu ideal de egoísmo, mas retificá-lo, a fim de 'satisfazer sua concupiscência sem fazer mal aos outros' (La 74); ele ensina como dar a seu egoísmo uma forma compatível com a vida social. Aí está um exemplo perfeito do resultado que se obtém quando se sabe 'regrar sua vida' (72) 'regular o amor que se deve a si mesmo' (368)". THIROUIN. Le hasard et les règles: le modèle du jeu dans la pensée de Pascal, p.69).

19 Sobre a crítica de Pascal ao honnête-homme, ver MESNARD. Les Pensées de Pascal, p. 117 et seq., chap. II. 
dos homens". ${ }^{20}$ Mesnard vai além, e se refere ao libertin-honnête-homme como uma figura única. ${ }^{21}$ Se é assim, como os homens caracterizados em primeiro lugar no fragmento La 427, estes últimos também não seriam razoáveis, pois é fácil compreender que há uma contradição entre a busca da felicidade e a indiferença quanto ao destino da alma.

Pascal, porém, levanta a hipótese de ser essa indiferença apenas um fingimento que o honnête-homme julga ser do agrado do outro; ele finge a descrença com um objetivo maior. Seu sentimento, portanto, não estaria completamente corrompido. A diferença entre as duas figuras coloca-se então no âmbito do sentimento: é certo que o honnête-homme não busca a Deus, mas ele pode ainda, diferentemente do incrédulo, sentir-se infeliz com sua situação. Tanto é assim que Pascal recomenda: "Se eles estão constrangidos no fundo de seu coração por não terem mais luzes, não o dissimulem." (La 427) Tal diferença tem um papel muito essencial, pois abre ao honnête-homme a possibilidade de transformar-se em alguém que busca.

Ao sentimento a respeito do destino da alma se opõe, na perspectiva do honnête-homme, outro sentimento: o desejo de ser amado. Como vimos no trecho de Méré citado acima, a busca da estima dos outros é a essência do amor-próprio no honnête-homme, o qual reconhece de forma inequívoca que sua felicidade depende do amor e da estima dos outros. Precisamente, o amor-próprio se define como busca do amor de um outro. Pascal quer mostrar, no entanto, que os dois sentimentos - preocupação com o destino da alma e busca da estima dos outros - não são contraditórios, pois uma pessoa racional não estimaria uma atitude tão irracional como a que exibem os incrédulos. Podemos pensar, aqui, que a busca do amor de um outro é também, para Pascal, um componente essencial da natureza humana e, talvez por isto, o honnête-homme pode escapar da categoria da corrupção de segundo grau. A necessidade da estima dos homens figura a necessidade do amor de Deus. Ausente no retrato do primeiro tipo de homem, o incrédulo, esta forma de amor representa, no honnête-homme, uma possível passagem para a busca da alteridade infinita: só ela capaz de levar o ser humano para uma vida razoável, senão feliz.

Como conclusão, retomemos as principais afirmações que podemos estatuir da leitura do fragmento La 427:

1- A centralidade do sentimento para a definição dos tipos de homem: não podemos retomar toda a riqueza deste termo em Pascal; neste fragmento 
ele significa, sobretudo, a capacidade de sentir a infelicidade da condição humana.

2- $\mathrm{O}$ primeiro tipo de homem retratado no fragmento, o incrédulo, o é através de uma imagem da integridade, da unidade, da finitude: ele se fecha e se contenta em si, sem viver as contradições de sua existência. Este tipo representa a corrupção total da natureza. Embora não analisado neste fragmento, do lado oposto do descrente, encontra-se o cristão que, se de fato não supera todas as contradições nesta vida, articula a dualidade da miséria e da grandeza sob a luz de uma história sagrada e vive os sinais da unidade no pertencimento ao Corpo.

3- Entre esses dois tipos, a pessoa que busca a Deus pode ser considerada como a figura emblemática da natureza humana decaída, não unívoca, mas contraditória, pois não coincide consigo mesma: ela quer sair da dúvida na qual se encontra. Através desta figura, Pascal faz o elogio do amor-próprio que, no entanto, só é louvado na medida em que sente seu fracasso.

4- O último tipo começa a se delinear, não muito claramente, entre a figura do incrédulo e a do que busca: o honnête-homme. Por um lado, ele não se dedica a buscar a Deus, por outro, ele apenas finge indiferença quanto ao seu destino. Portanto, não coincide consigo mesmo. Por causa dessa dualidade, podemos afirmar que ele se aproxima mais da figura do que busca que da figura do descrente.

\section{Referências Bibliográficas}

BIRCHAL, T. A marca do vazio: reflexões sobre a subjetividade em Blaise Pascal. Kriterion, v. 88, p. 50-69, 1993.

MACKENNA, A. Une question de cohérence: l'argument ad hominem dans les Pensées de Pascal. Littératures Classiques, n. 20, p. 23-43, jan. 2004.

MÉRÉ, A. G. De la vraie honnêteté. In: MERE, Chevalier. Euvres complètes. Paris: Ed. Fernand Roches, 1930.

MESNARD, J. Les Pensées de Pascal. Paris: Societé d'Édition de l'Enseignement Supérieur, 1976.

MESNARD, J. Les origines grecques de la notion d'amour-propre. In: . $L a$ culture du XVII ${ }^{\text {eme }}$ siècle. Paris: PUF, 1992.

MICHON, H. L'ordre du cæur: philosophie, théologie et mystique dans les Pensées de Pascal. Paris: Honoré-Champion, 1996.

PASCAL, B. Lettre écrite à l'occasion de la mort de M. Pascal le Pére. In: Euvres complètes. Apresentação e notas de Louis Lafuma. Paris: Seuil, 1963. . Pensamentos. Trad. Mário Laranjeira. São Paulo: Martins Fontes, 2001. . Pensamentos. Trad. Sérgio Milliet. São Paulo: Abril Cultural, 1979. 
PINTARD. R. Pascal et les libertins. In: Pascal Présent (1662-1962). Collections Ecrivains d'Auvergne. Clermont-Ferrant: [s. n.], 1962, p. 107-130.

SELLIER, P. Pascal et Saint-Augustin. Paris: Armand Colin, 1970. . L'ouverture de l'Apologie. In: . Port-Royal et la littérature.

Paris: Honoré-Champion, 2000.

THIROUIN, L. Le hasard et les règles: le modèle du jeu dans la pensée de Pascal. Paris: Vrin, 1991.

WETZEL, D. Pascal and desbelief: cathechesis and conversion in the Pensées. Washington, DC: The Catholic University of America Press, 1994. 